\title{
The Efficiencies of Cellulose Acetate Filters *
}

\author{
by $R$. W. Dwyer and S. G. Abel \\ Philip Morris Research Center, Richmond, Virginia, U.S.A.
}

\section{SUMMARY}

Cigarette filters remove both particles and condensable vapors from tobacco smoke aerosols. The particulate contribution to filtration can be isolated by allowing the smoke aerosol to attain thermal equilibrium before it is introduced to the filter. Such experiments show the effects of filter length, filter pressure drop, and aerosol flow rate on particulate filtration. The relative roles of diffusion, impaction, and interception on particle removal have been examined. The extent to which vapor condensation occurs in filters has been found to be dependent on the length to which the tobacco rod has been smoked and independent of the pressure drop of the filter.

\section{ZUSAMMENFASSUNG}

Sowohl feste Partikel wie auch kondensierbare Gase werden durch Zigarettenfilter aus dem Tabakrauchaerosol entfernt. Der Filtrationsanteil, dem die Partikelphase unterliegt, kann dadurch isoliert werden, $d a ß$ das Rauchaerosol dem Filter erst zugeführt wird, nachdem es ein thermisches Gleichgewicht ausbilden konnte. Durch Versuche dieser Art wird erkennbar, inwieweit die Partikelretention von der Lănge und dem Zugwiderstand des Filters und von der Strömungsgeschwindigkeit des Rauchaerosols bestimmt wird. Der relative Anteil von Diffusion, Impaktion und Abfangen am Retentionsvorgang wurde untersucht. Das Ausmaß der Kondensation der Gasphase im Filter erwies sich als abhängig von der jeweils verrauchten $L a ̈ n g e$ des $T$ abakstranges und als unabhängig vom Druckabfall im Filter.

\footnotetext{
* Received: 4th June 1985 - accepted: 25th February 1986
}

\section{RESUME}

Les filtres de cigarettes retiennent à la fois les particules solides et les vapeurs condensables contenues dans l'aérosol de la fumée de tabac. La partie filtrée qui provient de la phase particulaire peut être isolée si l'on n'introduit l'aérosol dans le filtre qu'une fois l'équilibre thermique établi. Des expériences de ce type permettent de mettre en évidence l'influence qu'exercent la longueur et la résistance au tirage du filtre ainsi que le débit de l'aérosol sur la rétention des particules. Les rôles respectifs de la diffusion, de l'impact et de l'interception dans le phénomène de rétention ont été étudiés. L'importance de la condensation de la phase gazeuse dans le filtre est fonction de la longueur du boudin de tabac ayant été fumé tandis qu'elle est indépendante de la résistance au tirage du bout-filtre.

\section{INTRODUCTION}

Cigarette filters not only remove particulate matter from tobacco smoke, but they also provide surfaces for vapor condensation. This latter role is often overlooked. The smoke removal efficiencies of fibrous cigarette filters have been extensively studied, yet few reports have included vapor condensation contributions explicitly. This neglect arises because the smoke aerosol rapidly changes as it travels through the filter. Both the particle size distribution and the partitioning between particulate and vapor phases may undergo dramatic shifts during the aerosol's residence time in the filter. These complicating features of aerosol behavior are usually ignored and the system is most often treated as if vapor/particulate equilibrium exists.

In this study we have attempted to isolate the particu- 
late contribution to filtration. This was accomplished by allowing cigarette smoke sufficient time to achieve vapor/particulate equilibrium before introducing it to filter samples. The effects of aerosol concentration, aerosol velocity, filter length and filter pressure drop on filtration efficiency have been examined. These results have been used to separate conventionally measured filter efficiencies into their particulate and condensable-vapor contributions.

\section{CONVENTIONAL FILTRATION EFFICIENCIES}

Cigarette filter efficiencies are conventionally measured with a gravimetric procedure performed under standard smoking conditions. In this procedure, the smoke is generated by a reference tobacco rod. The rod is directly attached to a test filter by means of a glass sleeve. The cigarette filter is connected to the holder of a high-efficiency particulate filter pad (HEP). The HEP retains $99.9 \%$ of particles with diameters equal to or exceeding $0.3 \mu \mathrm{m}$. The cigarette is smoked by taking $35.0 \mathrm{~cm}^{3}$ puffs of $2.0 \mathrm{~s}$ duration at a uniform rate $\left(17.5 \mathrm{~cm}^{3} / \mathrm{s}\right)$. Puffs are taken at $60.0 \mathrm{~s}$ intervals until some preselected length of the tobacco rod is consumed. The efficiency (E) is determined from the weight gains of the cigarette filter and the HEP according to the relationship:

$$
E=w_{f} /\left(w_{f}+w_{p}\right),
$$

where $w_{f}$ and $w_{p}$ are the weights of material collected by the cigarette filter and the HEP, respectively. All materials are allowed to condition for twenty-four hours at $60 \pm 2 \%$ relative humidity and $23.8 \pm 0.6^{\circ} \mathrm{C}$ before testing. The efficiency tests are performed in a laboratory maintained at the same temperature and humidity conditions.

In order to evaluate the contributions of vapor condensation to filtration efficiencies measured in this manner, experiments were performed in which the length of tobacco rod consumed was varied. We envision the condensation process as one in which a zone of condensable vapors collects on the material downstream of the burning coal. As the cigarette is smoked, this zone moves toward the filter (1). Tobacco rods $10.0 \mathrm{~cm}$ in length were smoked to butt lengths ranging from 1.5 to $7.5 \mathrm{~cm}$. Five types of cellulose acetate filters were used in the efficiency determinations. The filters were $2.47 \mathrm{~cm}$ in circumference and unventilated. They were selected such that their pressure drops, $\Delta \mathrm{P}$, at $17.5 \mathrm{~cm}^{3} / \mathrm{s}$ were within $\pm 0.2 \mathrm{~cm}$ w.g. of the target.

The results of these experiments are illustrated in Figure 1 and Table 1. The closer the cigarette coal is to the filter, the greater the conventionally measured filtration efficiency. Our hypothesis is that this increase in efficiency is due to an increase in the amount of condensed vapors on the filter rather than an increase in its particulate removal efficiency.
Figure 1.

Conventionally measured filtration efficiencies (E) of flve tow Items as functions of the tobacco rod length $\left(L_{b}\right)$ to which the samples were smoked.

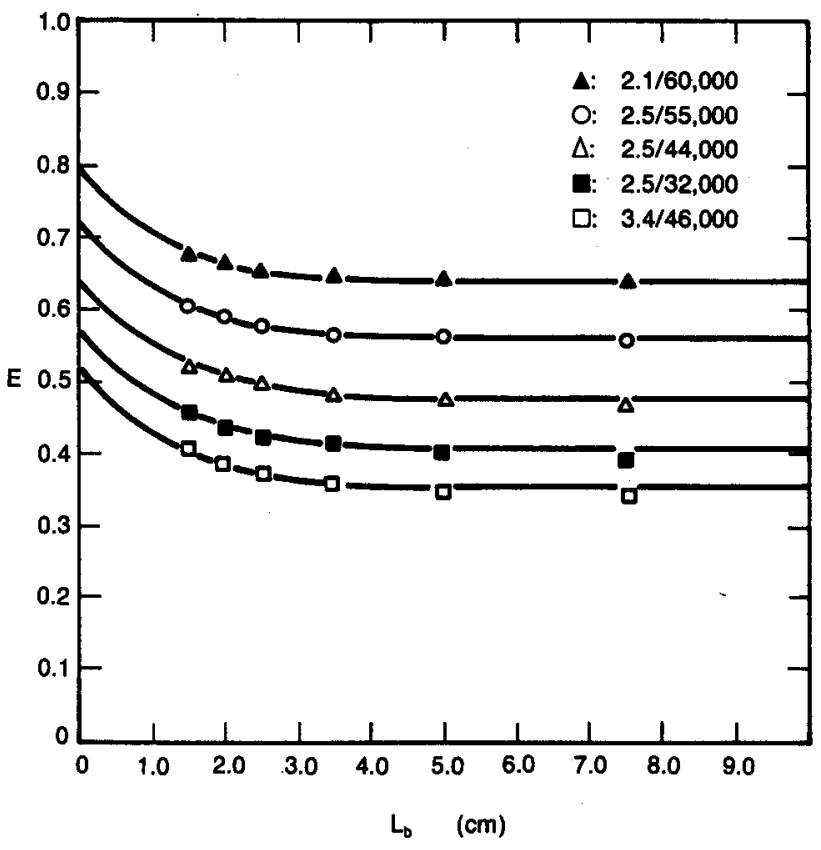

This explanation differs from that proposed by MathIs (2). In performing a similar filtration efficiency study, he reported the change in efficiency of a cellulose acetate filter into which cigarette smoke was introduced. $\mathrm{He}$ found that the filter section closest to the tobacco rod displayed a higher efficiency than subsequent sections. MatHrs attributed this observation to changes in the particle size distribution of the smoke aerosol as it passes through the filter. He concluded that such filters preferentially remove larger particles, thereby exposing downstream segments to an aerosol of ever diminishing size.

MCRAE (3), on the other hand, reported calculations which showed the mean particle size of tobacco smoke aerosols to be little affected by filter length, over length ranges commonly found in cigarettes. Using an assumed smoke aerosol distribution, McRAe computed the removal efficiencies of cellulose acetate cigarette filters for the particle-size dependent mechanisms of diffusion, impaction, and interception. He found that the number of particles could be profoundly affected by filter length, but the moments of the distribution were essentially unchanged.

Tshizu, Ohta and Orada (4) described their experimental results on the effects of tobacco rod lengths on the size distribution of the smoke aerosol. They found that the longer the tobacco column from which a puff is taken, the larger the mean particle size of the mainstream smoke emerging from it. Based on this result and Mathrs' conclusion, one would expect the filtration efficiencies we measured to decrease with decreasing butt length, in direct contrast to the behavior illustrated in Figure 1. 
Table 1.

Conventionally measured filter efficiencles (\%).

\begin{tabular}{c|ccccc}
\hline $\begin{array}{c}\text { Butt length }\left(L_{b}\right) \\
(\mathrm{cm})\end{array}$ & $2.1 / 60,000$ & $2.5 / 55,000$ & $2.5 / 44,000$ & $2.5 / 32,000$ & $3.4 / 46,000$ \\
\hline 1.5 & 68 & 61 & 52 & 46 & 43 \\
2.0 & 66 & 60 & 51 & 54 & 42 \\
2.5 & 66 & 58 & 48 & 42 & 38 \\
3.5 & 65 & 56 & 48 & 40 & 39 \\
5.0 & 64 & 56 & 46 & 36 & 34 \\
7.5 & 64 & 56 & 11.2 & 7.9 & 7.1 \\
\hline
\end{tabular}

\section{PARTICULATE FILTRATION EFFICIENCIES}

In order to minimize the condensation effect, we designed an experimental apparatus which allows the vapor phase to reach equilibrium before it is introduced into the filter.

A schematic of the apparatus used for these experiments is shown in Figure 2. A five-port sequential smoking machine was used in this study. The output port of the smoking machine was attached to an $80 \mathrm{~cm}$ length of Tygon tubing (the aerosol delay tube) having a $0.8 \mathrm{~cm}$ internal diameter. There were two branches at the end of this tubing. One led to a three-way solenoid valve, a mass flow meter, and a flow controller which maintained a constant flow rate of $17.5 \mathrm{~cm}^{3} / \mathrm{s}$. The second branch led to a three-way solenoid valve, a sample holder, a high-efficiency filter pad (HEP), a flow meter, and a flow controller. Both flow controllers were connected in parallel to a common pump.

The sample holder consisted of copper tubing $1.2 \mathrm{~cm}$ in internal diameter with an inner sleeve of thin-walled, air-impermeable rubber tubing. The rubber tubing was

Figure 2.

Schematic of the

particulate efficlency apparatus.

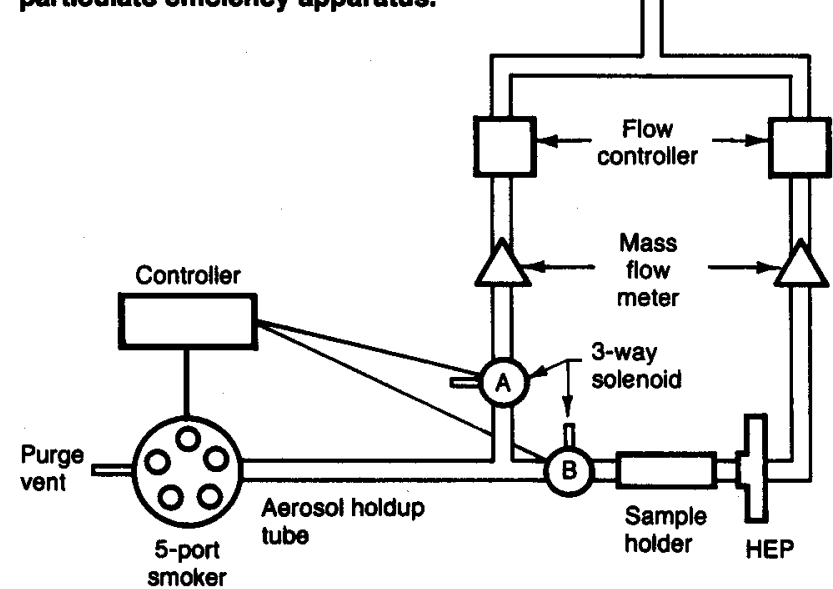

vacuum expanded to admit filter samples, and then collapsed to hold them in place. This arrangement did not measurably alter the pressure drops of the filter samples.

The sequence of an experiment was as follows: The flow in branch A (Figure 2) was maintained at $17.5 \mathrm{~cm}^{3} / \mathrm{s}$, and that in branch $B$ was an experimental variable. The latter flow controlled the velocity of the smoke aerosol through the filter sample and was set at some selected value at the start of a run. The smoking machine was programmed to puff on the first cigarette for two seconds, thereby filling the aerosol delay tube, and to purge for ten seconds, during which time the aerosol was introduced to the filters in the sample holder. Then, each of the other four cigarettes would undergo the two-second-puff/ten-second-purge cycle in turn. This sequence continued until each had been smoked for six puffs. The timing cycle gave rise to the standard smoking conditions of a two-second puff and a sixtysecond interval between consecutive puffs on any one cigarette.

During puffing, solenoid A was open to the smoking machine, and solenoid $B$ was open to the atmosphere. During the ten-second purge, solenoid B was open to the aerosol delay tube, and solenoid $\mathrm{A}$ was vented to the atmosphere. Thus, the cigarettes were always puffed at $17.5 \mathrm{~cm}^{3} / \mathrm{s}$, and the smoke aerosol was pulled through the filter samples at the selected flow rate.

Unfiltered tobacco rods were used in the smoking machine to generate the aerosol. The experiments were performed in an environment maintained at $60 \pm 2 \%$ relative humidity and $23.8 \pm 0.6^{\circ} \mathrm{C}$. All of the filters and tobacco rods were equilibrated at these conditions prior to testing. The filtration efficiencies for these determinations were computed using equation 1.

\section{RESULTS}

The purpose of the aerosol delay tube was to allow vapor-liquid equilibrium to become established before the aerosol challenged the filter. The results of our experi- 
Figure 3.

The mass of particulate matter removed by series of filters in tandem vs. the mass of material to which they were exposed.

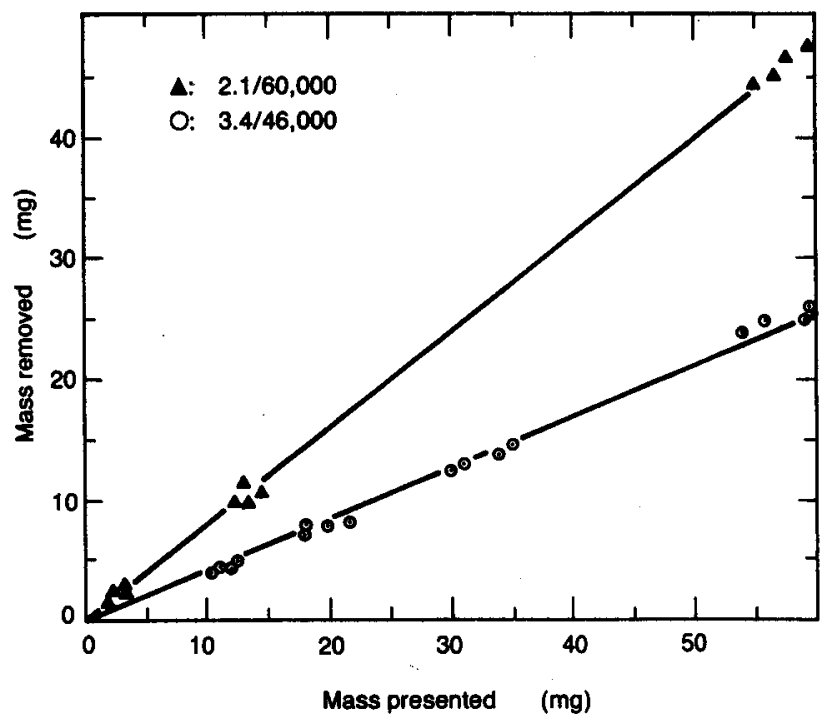

ments show that condensation effects were not a significant factor in these efficiency measurements.

Typically, a run consisted of placing four filters in series, abutting each other, in the sample holder, and subjecting them to smoke from the aerosol delay tube. In Figure 3, we present plots of the aerosol mass entering each of the samples in the holder vs. the mass retained by each at a flow rate of $17.5 \mathrm{~cm}^{3} / \mathrm{s}$. For the filter tows used in this study, the four points from each sample lie along a straight line indicating that every member of a series had the same efficiency. The slope of this line is equal to the filtration efficiency of each section. The linear response was demonstrated at all of the flow rates investigated.

This linear behavior reflects on several aspects of filtration: (a) the extent of vapor condensation, (b) the effects of aerosol concentration and accumulation, and (c) the role of aerosol particle sizes on filter selectivity.

Since each of the four members of a series retained the same fraction of available aerosol, condensation was not playing a significant role in these measurements. We would anticipate the first filter of the series to have a greater mass accumulation than the last if condensation were occurring. Therefore, this experimental technique does not suffer the same limitations as the conventional efficiency determination where non-equilibrated smoke is directly introduced to the filter. The aerosol delay tube provides sufficient time for the smoke aerosol to achieve vapor-particulate equilibrium before its introduction into the filters.

The linear behavior also shows that the concentration of aerosol challenging the filter has little effect on its efficiency. The data in Figure 3 show that the first filters were exposed to much more aerosol than the last, yet both demonstrated equivalent removal efficiencies.
Thus, the filter's efficiency for particulate removal is independent of the tobacco rod delivery within the range of normal cigarette deliveries. Furthermore, the first filter in the series accumulated considerably more material than the last, but both segments had equal efficiencies. Therefore, conventional cellulose acetate tow filters do not become more efficient as their loadings increase, within the range of normal deliveries.

A final consideration involves the particle size selectivity of the filters. If their removal efficiencies were strongly dependent on the sizes of the aerosol particles, one would expect the downstream sections to be exposed to a different aerosol size distribution than their upstream counterparts, as suggested by MatHIs (2). However, since each demonstrates equivalent efficiencies, this effect must not play a major role in filter mass accumulation, in agreement with MCRAE's prediction (3).

\section{A. The Effects of Filter Length}

Since the efficiencies of identical filters placed in series are equivalent, a recursive relationship can be developed between the efficiency of a single filter and the cumulative efficiency of the entire series. Consider a group of $\mathbf{N}$ filters aligned in tandem and presented with a mass $\mathbf{M}_{0}$ of aerosol. Let $\varepsilon$ denote the individual efficiency of each member. The mass of material penetrating the first filter will be $M_{0}(1-\varepsilon)$, the amount penetrating the second will be $M_{0}(1-\varepsilon)^{2}$ and, in general, the amount penetrating filter section $i$ will be $M_{0}(1-\varepsilon)^{i}$.

\section{Figure 4.}

Semilogarlthmic plot of particulate penetration (1 - E) vs. filter length (L) at a flow rate of $17.5 \mathrm{~cm}^{3} / \mathrm{s}$.

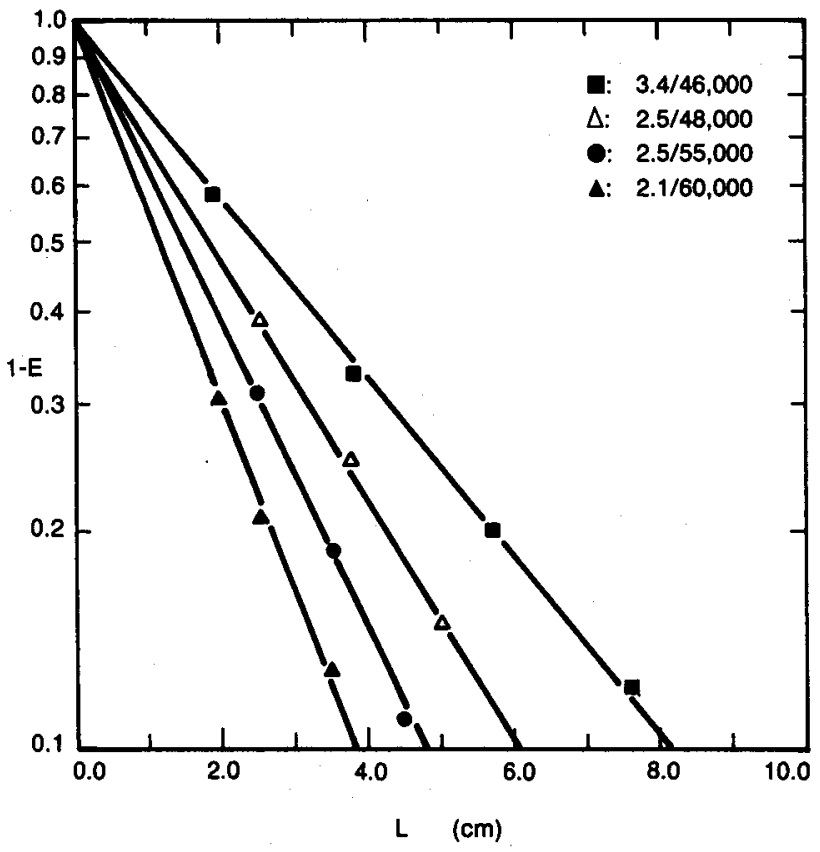


The total efficiency of the train of $\mathrm{N}$ identical filters is therefore:

$$
\mathrm{E}=1-(1-\varepsilon)^{\mathrm{N}}
$$

If we assume each filter to be of unit length, having an efficiency $\varepsilon_{\mathrm{p}}$, and that there are $L$ unit lengths, then equation 2 may be rewritten:

$$
E=1-\left(1-\varepsilon_{1}\right)^{\mathrm{L}} \text {. }
$$

Therefore, for a filter $\mathrm{L}$ centimeters long with a total efficiency of $E, \varepsilon_{l}$ is the efficiency contribution of each centimeter section. The value of $\varepsilon_{1}$ can be calculated from $E$ and $L$ measurements using the rearranged form of equation 3:

$$
\varepsilon_{1}=1-(1-E)^{1 / L}
$$

or from the slope of $\ln (1-E)$ vs. L plots:

$$
\ln (1-E)=L \ln \left(1-\varepsilon_{1}\right) \text {. }
$$

Figure 4 illustrates the latter technique for a variety of cellulose acetate tow filters at an aerosol flow rate of $17.5 \mathrm{~cm}^{3} / \mathrm{s}$. Thus, each type of filter, at each flow rate, has a characteristic value of $\varepsilon_{1}$ (Table 2).

FORDYCE, Hughes and Ivinson (5) derived an equation relating efficiency and filter length in the form:

$$
E=1-e^{-k L},
$$

where $\mathrm{k}$ is a characteristic of the filter material which

\section{Figure 5.}

Semllogarithmlc plot of particulate penetration (1 - E) vs. filter pressure drop $(\triangle P)$ at a flow rate of $17.5 \mathrm{~cm}^{3} / \mathrm{s}$.

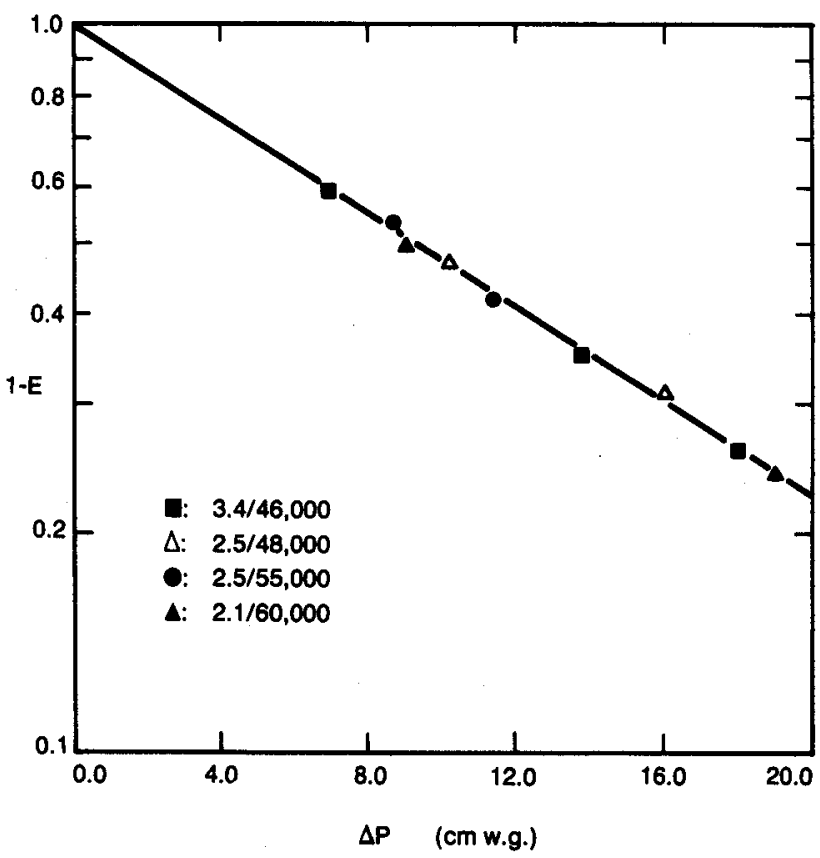

the authors called the coefficient of filtration. This relationship is mathematically equivalent to equation 3 where:

$$
\varepsilon_{1}=1-\mathrm{e}^{-\mathbf{k}}
$$

\section{B. The Effects of Pressure Drop}

In deriving equation 3 , we considered a filter train composed of sections of equal length. By considering sections of equal pressure drop, a direct analogue of this relationship can be written in the form:

$$
E=1-\left(1-\varepsilon_{p}\right)^{\Delta P},
$$

where $\varepsilon_{\mathrm{p}}$ is the filtration efficiency per unit of filter pressure drop. Therefore, by measuring the efficiency at a certain pressure drop, $\varepsilon_{\mathrm{p}}$ can be calculated from:

$$
\varepsilon_{\mathrm{p}}=1-(1-\mathrm{E})^{1 / \Delta \mathrm{P}}
$$

or it may be evaluated from the slope of $\ln (1-E)$ vs. $\Delta \mathrm{P}$ plots:

$$
\ln (1-E)=\Delta P \ln \left(1-\varepsilon_{p}\right)
$$

The data from Table 2 at $Q=17.5 \mathrm{~cm}^{3} / \mathrm{s}$ were graphed in the form of equation 10 and are illustrated in Figure 5. Notice that all of the tow results for this flow lie along the same straight line, i.e. the value of $\varepsilon_{\mathrm{p}}$ is a constant for these five tow items at $17.5 \mathrm{~cm}^{3} / \mathrm{s}$. If this behavior is generally true for such filters, the efficiency of any cellulose acetate tow filter can be predicted directly from its pressure drop.

\section{The Effects of Flow Rate}

The flow rate, $Q$, of the air entraining the smoke aerosol was varied from 1.67 to $50.0 \mathrm{~cm}^{3} / \mathrm{s}$. At each flow rate, the pressure drops and efficiencies of the filters were measured with three to five replicate runs. Figure 6 illustrates the variation of filter pressure drop with flow, and Figure 7 shows the effects of flow rate on efficiency. By means of the graphical techniques embodied in equations 5 and 10 , the values of $\varepsilon_{1}$ and $\varepsilon_{\mathrm{p}}$ were evaluated. These results are given in Table 2. Figure 8 illustrates the functional dependence of $\varepsilon_{\mathrm{p}}$ on the rate at which the smoke aerosol passed through each type of filter. The relationship between $\varepsilon_{p}$ and $Q$ is the most interesting to pursue since, at any particular flow rate, all five types of filters displayed the same value of $\varepsilon_{\mathrm{p}}$. This constancy allows us to treat the data from all of the samples with one equation.

Magee, Jonas and Anderson (6) have published a review of the semiempirical formalisms for evaluating aerosol filtration. They developed a relationship be- 
Table 2.

Experimental data for particulate efficlency atudy.

\begin{tabular}{|c|c|c|c|c|c|}
\hline $\begin{array}{c}Q \\
\left(\mathrm{~cm}^{3} / \mathrm{s}\right)\end{array}$ & $\begin{array}{c}\mathrm{L} \\
(\mathrm{cm})\end{array}$ & $\begin{array}{c}\Delta P \\
\text { (cm w.g.) }\end{array}$ & $E \pm \sigma$ & $\begin{array}{c}\varepsilon_{1} \\
\left(\mathrm{~cm}^{-1}\right)\end{array}$ & $\begin{array}{c}\varepsilon_{p} \\
\left([\mathrm{~cm} \text { w.g. }]^{-1}\right)\end{array}$ \\
\hline \multicolumn{6}{|l|}{$2.1 / 60,000$} \\
\hline 1.7 & 2.5 & 1.8 & $0.927 \pm 0.023$ & 0.65 & 0.84 \\
\hline 3.3 & 2.5 & 4.6 & $0.920 \pm 0.021$ & 0.64 & 0.54 \\
\hline 6.7 & 2.5 & 7.6 & $0.860 \pm 0.029$ & 0.55 & 0.23 \\
\hline 11.7 & 2.5 & 14.5 & $0.810 \pm 0.042$ & 0.48 & 0.11 \\
\hline 16.7 & 2.5 & 20.8 & $0.790 \pm 0.027$ & 0.47 & 0.072 \\
\hline 19.2 & 2.5 & 22.9 & $0.786 \pm 0.010$ & 0.46 & 0.065 \\
\hline 21.7 & 2.5 & 27.4 & $0.778 \pm 0.011$ & 0.45 & 0.053 \\
\hline 25.0 & 2.5 & 31.5 & $0.790 \pm 0.005$ & 0.47 & 0.047 \\
\hline 33.3 & 2.5 & 43.2 & $0.766 \pm 0.015$ & 0.44 & 0.033 \\
\hline 50.0 & 2.5 & 66.5 & $0.766 \pm 0.021$ & 0.44 & 0.023 \\
\hline \multicolumn{6}{|l|}{$2.5 / 55,000$} \\
\hline 1.7 & 2.5 & 1.3 & $0.897 \pm 0.018$ & 0.60 & 0.84 \\
\hline 3.3 & 2.5 & 2.5 & $0.840 \pm 0.006$ & 0.52 & 0.54 \\
\hline 6.7 & 2.5 & 6.4 & $0.774 \pm 0.009$ & 0.45 & 0.23 \\
\hline 11.7 & 2.5 & 11.2 & $0.727 \pm 0.018$ & 0.41 & 0.11 \\
\hline 16.7 & 2.5 & 16.0 & $0.688 \pm 0.073$ & 0.38 & 0.072 \\
\hline 33.3 & 2.5 & 33.5 & $0.679 \pm 0.003$ & 0.36 & 0.033 \\
\hline 50.0 & 2.5 & 51.3 & $0.701 \pm 0.013$ & 0.38 & 0.023 \\
\hline \multicolumn{6}{|l|}{$2.5 / 48,000$} \\
\hline 1.7 & 2.5 & 0.8 & $0.839 \pm 0.018$ & 0.52 & 0.84 \\
\hline 3.3 & 2.5 & 1.8 & $0.793 \pm 0.034$ & 0.47 & 0.54 \\
\hline 6.7 & 2.5 & 4.3 & $0.665 \pm 0.009$ & 0.36 & 0.23 \\
\hline 11.7 & 2.5 & 8.4 & $0.631 \pm 0.021$ & 0.33 & 0.11 \\
\hline 16.7 & 2.5 & 11.4 & $0.608 \pm 0.019$ & 0.31 & 0.072 \\
\hline 19.2 & 2.5 & 13.0 & $0.578 \pm 0.010$ & 0.29 & 0.065 \\
\hline 21.7 & 2.5 & 15.7 & $0.577 \pm 0.022$ & 0.29 & 0.053 \\
\hline 25.0 & 2.5 & 17.0 & $0.559 \pm 0.013$ & 0.28 & 0.047 \\
\hline 33.3 & 2.5 & 23.4 & $0.587 \pm 0.012$ & 0.30 & 0.033 \\
\hline 50.0 & 2.5 & 32.0 & $0.617 \pm 0.021$ & 0.32 & 0.023 \\
\hline \multicolumn{6}{|l|}{$3.4 / 46,000$} \\
\hline 1.7 & 1.9 & 0.3 & $0.674 \pm 0.086$ & 0.44 & 0.84 \\
\hline 3.3 & 1.9 & 0.8 & $0.587 \pm 0.078$ & 0.37 & 0.54 \\
\hline 6.7 & 1.9 & 2.5 & $0.496 \pm 0.048$ & 0.30 & 0.23 \\
\hline 11.7 & 1.9 & 5.1 & $0.473 \pm 0.064$ & 0.29 & 0.11 \\
\hline 16.7 & 1.9 & 6.9 & $0.417 \pm 0.025$ & 0.25 & 0.072 \\
\hline 33.3 & 1.9 & 14.0 & $0.389 \pm 0.017$ & 0.23 & 0.033 \\
\hline 50.0 & 1.9 & 21.1 & $0.394 \pm 0.021$ & 0.23 & 0.023 \\
\hline
\end{tabular}


Figure 6.

Variation in the pressure drops $(\triangle \mathrm{P})$ of four cellulose acetate tow filters as functions of flow rate $(Q)$.

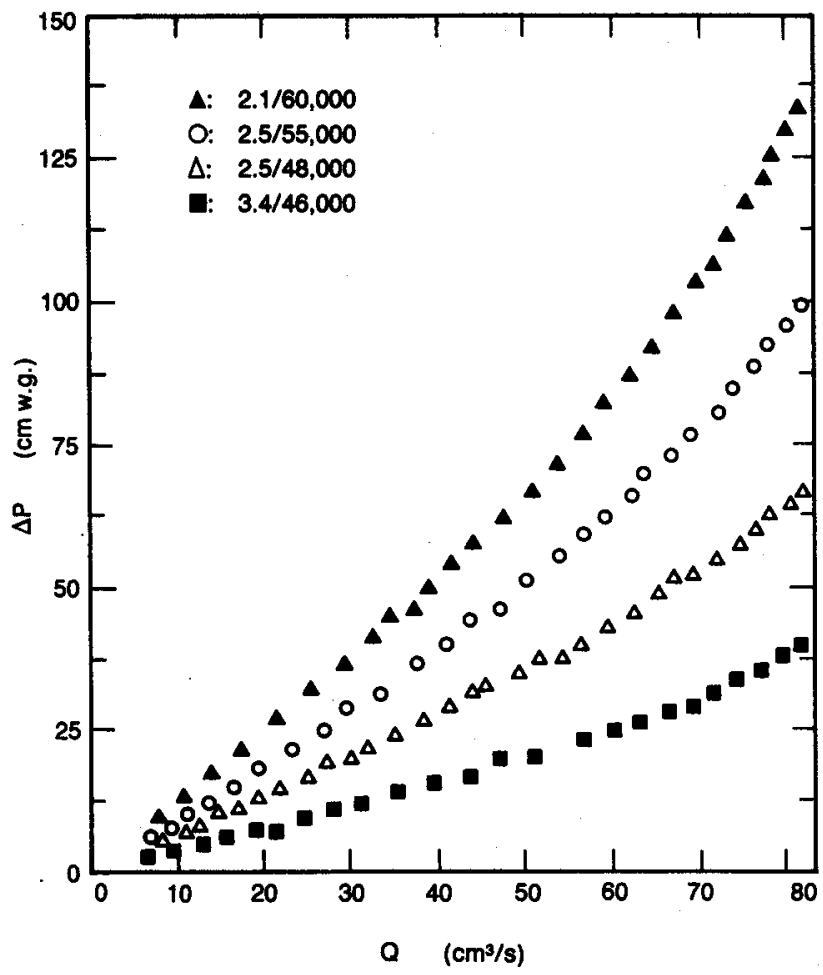

tween the efficiency of a filter and the velocity of the aerosol passing through it, assuming the flow to be laminar. Their treatment considers diffusion, intercep-

\section{Figure 8.}

Varlation in the efficiency per unit pressure drop $\left(\varepsilon_{p}\right)$ with aerosol flow rate $(Q)$. The points corresponding to KEITH's work were calculated from data in reference No. 10.

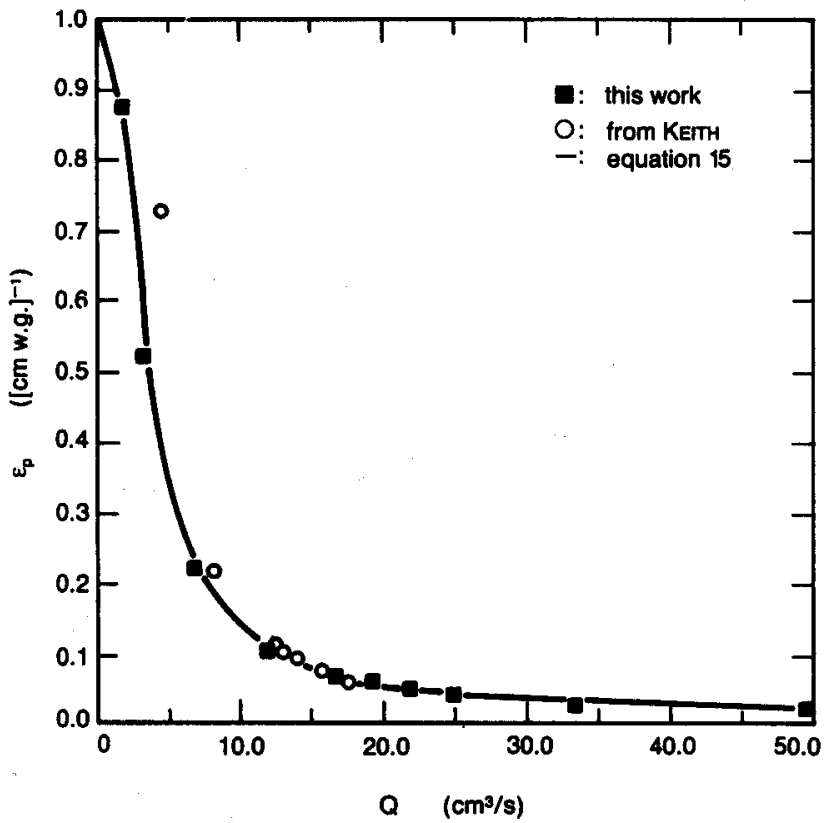

Figure 7.

Particulate filtration efficlencles (E) as functions of aerosol flow rate (Q).

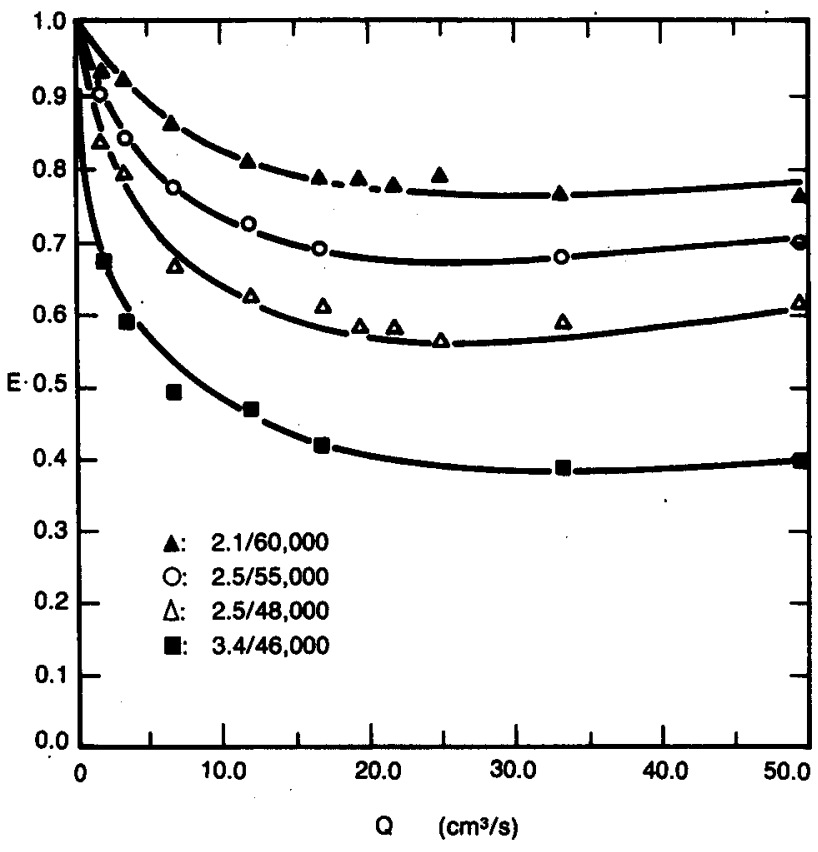

tion, and impaction as the dominant filtration mechanisms:

$$
\begin{aligned}
\ln (1-E)= & -C_{0} L-C_{1} L Q-C_{2} L Q^{-2 / 3} \\
& -C_{3} L Q^{-1}-C_{4} L Q^{-1 / 2} .
\end{aligned}
$$

The first term on the right-hand side of this equation is independent of flow rate and represents the interception factor, the second term is the impaction contribution, the third and fourth together account for diffusion, and the last represents the interaction of diffusion and interception. If gravitational settling is considered, an additional $\mathrm{Q}^{-1}$ term is introduced (7), but it is generally agreed that this mechanism is insignificant in tobacco smoke filtration. By making several further assumptions concerning the relative magnitudes of the factors in equation 11, MAGEE et al. simplified their expression to:

$$
\ln (1-E)=-C_{0} L-C_{1} L Q-C_{2} L Q^{-2 / 3}
$$

A similar equation was developed by Doorman (8) and applied to cigarette filters by OverTon (9).

The linear relationship between filter pressure drop and flow rate, as displayed in Figure 6, shows that the flow is laminar for these samples up to $50 \mathrm{~cm} / \mathrm{s}$. This observation allows us to write:

$$
\Delta \mathrm{P}=\left(\mathrm{Q} / \mathrm{Q}_{0}\right) \Delta \mathrm{P}_{0},
$$

where $\Delta \mathrm{P}_{0}$ is the pressure drop of a filter at the standard flow rate of $17.5 \mathrm{~cm}^{3} / \mathrm{s}\left(Q_{0}\right)$. 
Figure 9.

Variation of the particulate filtration processes with flow rate (Q).

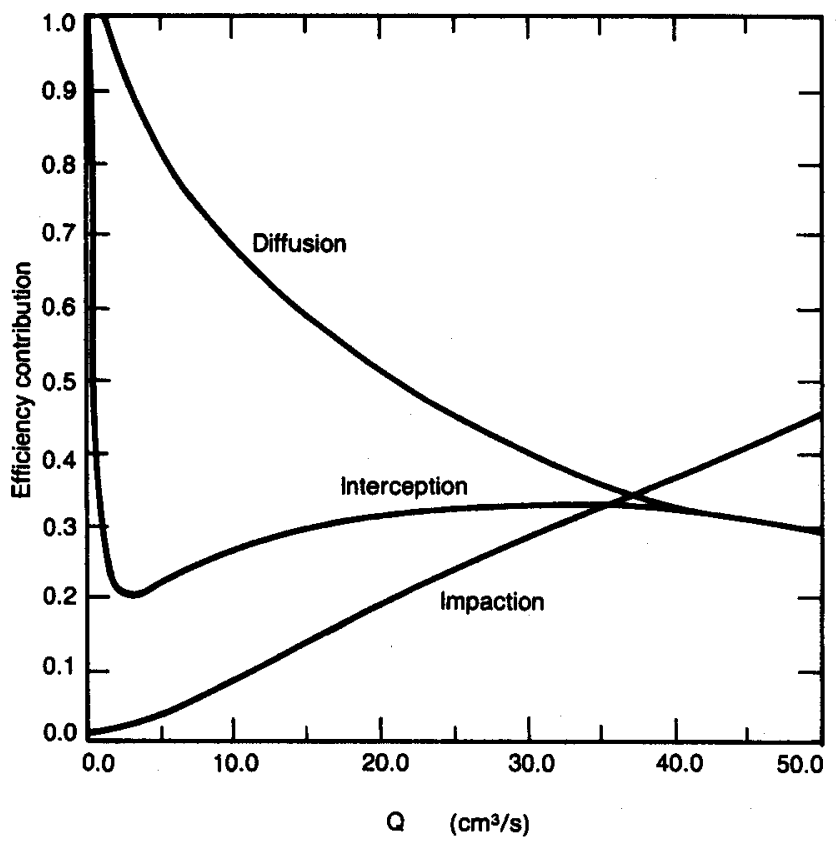

Substituting equations 10 and 13 into equation 12 gives:

$$
\begin{aligned}
\ln \left(1-\varepsilon_{\mathrm{p}}\right)= & -\left(\frac{\mathrm{C}_{1} L \mathrm{Q}_{0}}{\Delta \mathrm{P}_{0}}\right)-\left(\frac{\mathrm{C}_{0} L \mathrm{Q}_{0}}{\Delta \mathrm{P}_{0}}\right)^{\mathrm{Q}^{-1}} \\
& -\left(\frac{\mathrm{C}_{2} \mathrm{~L} \mathrm{Q}_{0}}{\Delta \mathrm{P}_{0}}\right)^{\mathrm{Q}^{-5 / 3}} .
\end{aligned}
$$

A weighted multiple regression in the form of equation 14 was performed on the data from Table 2 with the result:

$$
\ln \left(1-\varepsilon_{\mathrm{p}}\right)=-0.0111-0.371 \mathrm{Q}^{-1}-4.54 \mathrm{Q}^{-5 / 3} \text {. }
$$

The agreement between the predictions of this equation and the data is illustrated in Figure 8.

The first term on the right-hand side of equation 15 represents the impaction contribution to aerosol capture, the second arises from interception, and the third from diffusion. The relative contribution of each process is illustrated in Figure 9. Keep in mind that these are the contributions to $\varepsilon_{p}$, the efficiency per centimeter of pressure drop. Substituting equations 13 and 15 into equation 10 gives the following expression for the total particulate efficiency:

$$
\begin{aligned}
\mathrm{E}= & 1-\exp \left[-\Delta \mathrm{P}_{0}\left(2.12 \cdot 10^{-2}+6.34 \cdot 10^{-4} \mathrm{Q}\right.\right. \\
& \left.\left.+2.59 \cdot 10^{-1} \mathrm{Q}^{-2 / 3}\right)\right] .
\end{aligned}
$$

This expression was used to calculate the lines shown in Figure 7. Again, the agreement is quite good. This equation predicts that the minimum efficiency of the five filter samples occurs at a flow rate of $30 \mathrm{~cm}^{3} / \mathrm{s}$.

\section{VAPOR CONDENSATION}

Conventional filtration efficiency measurements include vapor condensation contributions as well as particulate accumulation. These total efficiencies can be partitioned into the contribution of each process. By assuming that the mechanisms of aerosol capture and vapor condensation act independently, the relationship can be written:

$$
E_{\mathrm{r}}=\mathrm{f}_{\mathrm{a}} \mathrm{E}_{\mathrm{a}}+\mathrm{f}_{\mathrm{c}} \mathrm{E}_{\mathrm{c}} \quad,
$$

where $E_{t}$ denotes the combined efficiency, and $E_{a}$ and $E_{c}$ are the efficiencies for particulate and vapor collection, respectively. The terms $f_{2}$ and $f_{c}$ represent the weight fractions of particulate and condensable matter to which a filter is exposed. These weight fractions are dependent on the tobacco rod properties and independent of the filter. Note that the sum of $f_{a}$ and $f_{c}$ is unity. Equation 17 describes the total efficiency as the massweighted average of the vapor and particulate efficiencies of a filter. The particulate efficiencies are those described in the previous section, e.g. equation 16.

The data presented in Table 1 were analyzed through the use of equation 17. These data are the total efficiencies of five types of filters measured as functions of the length to which the tobacco rods were smoked. In order to evaluate these results, $E_{a}$ was determined for each filter from equation 16. This equation yields the particulate efficiency in terms of the filter pressure drop and aerosol flow rate. The $\mathrm{E}_{\mathrm{a}}$ value of each filter was determined for the standard flow rate of $17.5 \mathrm{~cm}^{3} / \mathrm{s}$. Graphs of $E_{t}$ (Table 1) vs. $E_{2}$ (equation 16) for a given tobacco rod length proved linear, i.e. the efficiencies for the five filters fell about a single straight line. This behavior is illustrated in Figure 10 for two butt lengths. The five points describing each line represent the data for the five different filters. Therefore, the slopes $\left(f_{2}\right)$ and intercepts $\left(f_{c} E_{c}\right)$ of the lines are independent of the filter, but rather are functions of the butt length to which the tobacco rod was consumed during testing. This linear behavior is to be expected since $f_{a}$ and $f_{c}$ represent the smoke entering the filters. This observation shows the efficiency of each filter for collecting vapors to be the same at a given butt length for the five filter types since $f_{c}$ is a constant.

The weight fractions and vapor efficiencies at each butt length were evaluated from the slope and intercept of the corresponding $E_{\mathrm{a}}$ vs. $\mathrm{E}_{\mathrm{a}}$ graph.

$\begin{array}{cccc}L_{b}(\mathrm{~cm}) & f_{a} & f_{c} & E_{c} \\ 1.5 & 0.59 & 0.41 & 0.46 \\ 2.0 & 0.63 & 0.37 & 0.41 \\ 2.5 & 0.67 & 0.33 & 0.33 \\ 3.5 & 0.70 & 0.30 & 0.27 \\ 5.0 & 0.71 & 0.29 & 0.24 \\ 7.5 & 0.72 & 0.28 & 0.21\end{array}$


Figure 10.

Graph of the total filtration efficlencles $\left(E_{i}\right)$ vs. the particulate efficiencies (E, at two butt lengths. The flow rate was $17.5 \mathrm{~cm}^{3} / \mathrm{s}$.

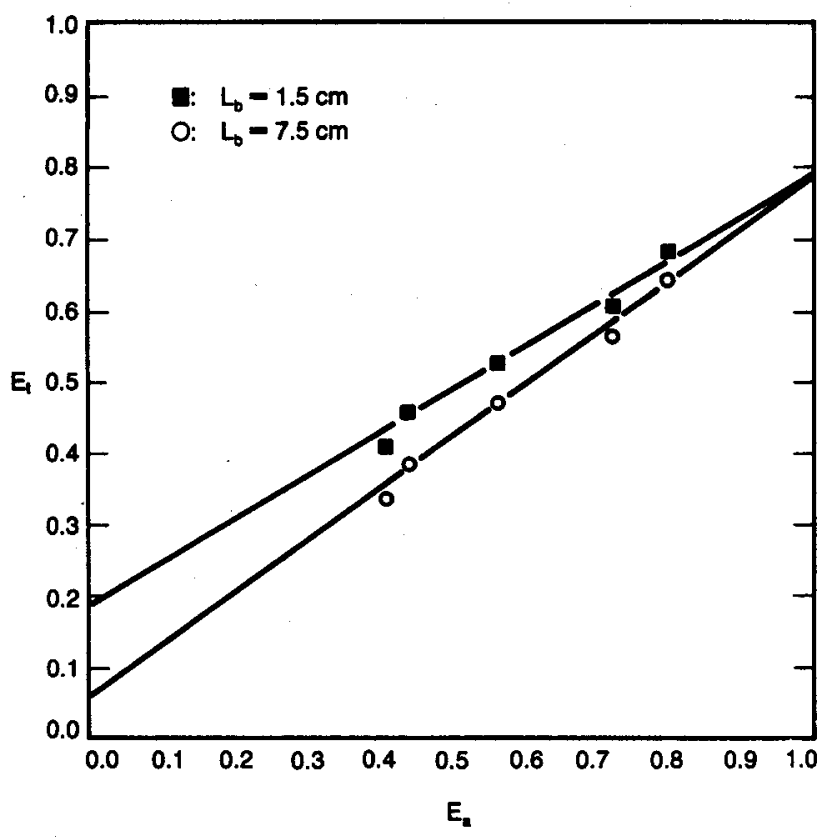

Figure 11 illustrates the effect of butt length on the relative amounts of vapor and particulate phases presented to the filters.

The lines in Figure 10 demonstrate a common point of intersection at an $E_{a}$ value of unity and an $E_{t}$ value of 0.78 . A graph of the six lines corresponding to the six butt lengths to which the samples were smoked, shows that all of the lines share this point of intersection. This observation indicates that the condensable vapors in the smoke emerging from the filters are a constant fraction of the smoke admitted to the filter, at all butt lengths:

$$
f_{c}\left(1-E_{c}\right)=0.22
$$

The quantity $f_{c}\left(1-E_{c}\right)$ represents the fraction of the smoke to which the filter was exposed, which penetrates in the form of condensable vapors. The commonality of the intersection point means that, regardless of the filter type or butt length, $22 \%$ of the smoke admitted to the filter emerges as condensable vapor. This result may be explained by the properties of the HEP. If the HEP is able to remove vapor-phase components which are inaccessible to the filter, then such a result would be expected. It is quite likely that the HEP, due to the materials of its construction and comparatively high pressure drop, has an ability to remove vapors which exceeds that of cellulose acetate filters. This explanation is speculative since no experimental verification has been performed.

An empirical relationship was obtained graphically be-
Figure 11.

Calculated particulate and condensable vapor fractions of the smoke presented to cigarette filters plotted as a function of butt length $\left(L_{b}\right)$.

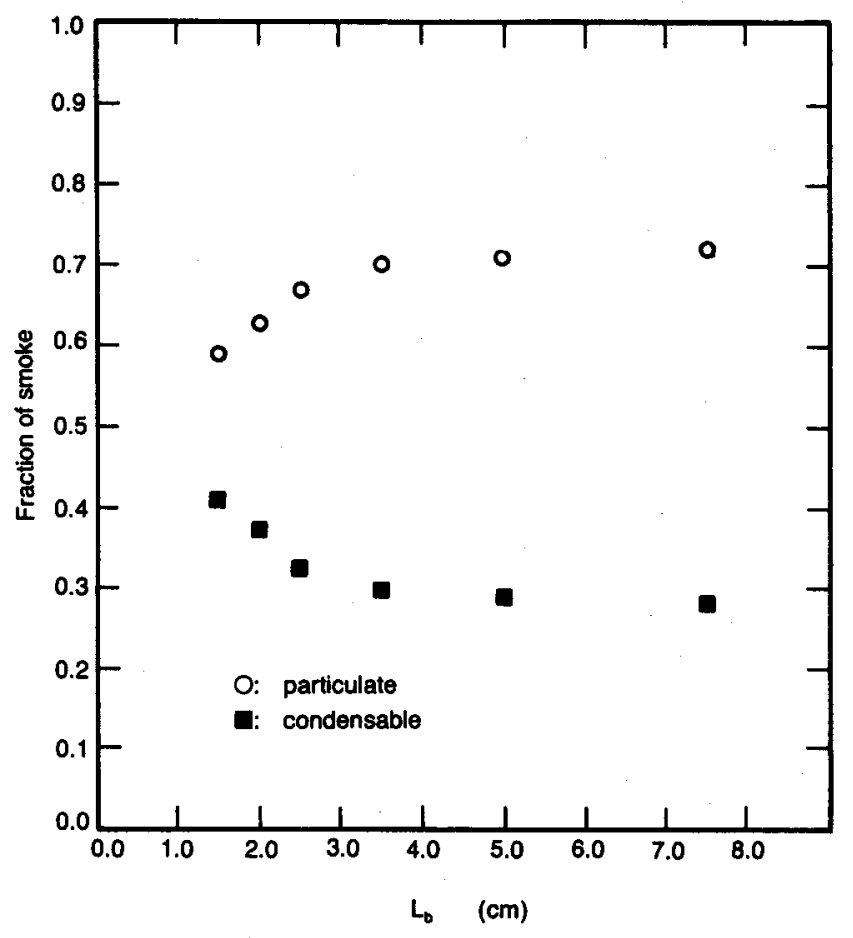

tween the vapor efficiency of the cigarette filters and the butt length:

$$
\mathrm{E}_{\mathrm{c}}=0.55 \mathrm{~L}_{\mathrm{b}}^{-1 / 2}
$$

As the butt length decreases, the temperature of the smoke increases and, therefore, the temperature difference between the smoke vapors and filter increase. As this temperature difference increases, the greater the rate of condensation and, therefore, the greater the filter efficiency for condensation.

\section{DISCUSSION}

Conventionally measured cigarette-filter efficiencies include contributions from both aerosol particle retention and the condensation of vapors. By inserting an aerosol delay tube between the tobacco rod and filter, this two-phase system can attain phase equilibrium. Under these conditions, vapor condensation in the filter is minimized, and the contributions of the particulate phase can be isolated. The results of such experiments with cellulose acetate filters show that their efficiencies are independent of the amount of aerosol to which they are exposed. These results also suggest that changes in the size distribution of the smoke aerosol as it passes through the filter have little effect on efficiency. 
Figure 12.

Comparison of the particulate efficiencies (E) calculated by KErTH (reference No. 10) and those calculated in this work uaing Kerth's data.

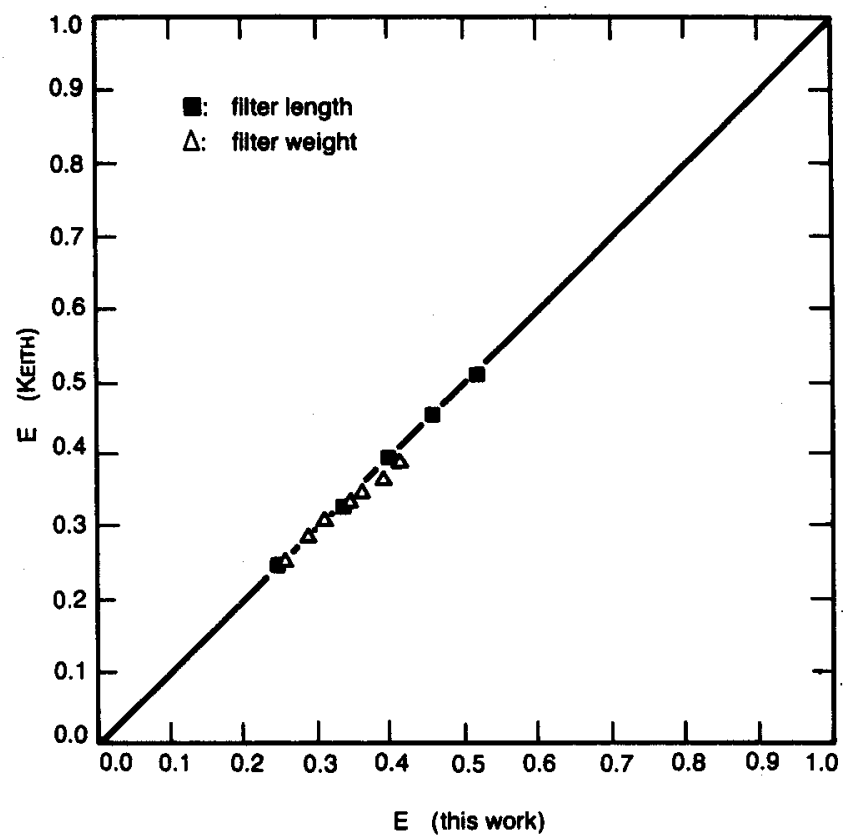

In addition to allowing equilibrium between the particulate and vapor phases of the aerosol, the delay tube also provided time for aerosol growth through condensation and coalescence. Since the smoke aerosol resided in the tube for at least two seconds prior to entering the filters, the resulting particle sizes may have been significantly larger than those of fresh smoke. Such a change in particle size could affect aerosol filtration due to the size dependence of filtration processes. Equation 12 does not explicitly account for particle size, although the coefficients of this expression are functions of the aerosol size distribution. The point to consider is the validity of using the coefficients of equation 16 for calculating the efficiencies of filters for fresh cigarette smoke. Experimental validation of this point is not practical since there is no way of which we are aware to generate fresh particulate phase in equilibrium with its vapors. An alternative is to compare our results for aged, equilibrated smoke with other models which are based on the actual particle size distributions of fresh smoke. One such model is that of KEITH (10). $\mathrm{K}_{\mathrm{EITH}}$ has reported a filtration model which explicitly accounts for the size distribution of cigarette smoke particles and the particle size dependence of impaction, interception, and diffusion (10). He has provided a table of calculated filter pressure drops and particulate efficiencies as functions of aerosol flow rate. Using these values, we calculated $\varepsilon_{\mathrm{p}}$ from equation 9 . The results are illustrated in Figure 8. The agreement between KEIrT's size-dependent model and our aged smoke results shows excellent correspondence at all but the lowest flow rate where the residence time in the delay tube was the greatest. Although this hardly constitutes veri-
Figure 13.

Comparison of the particulate efficlencles (E) calculated by KETH (reference No. 10) and those calculated in this work using KerTH's data.

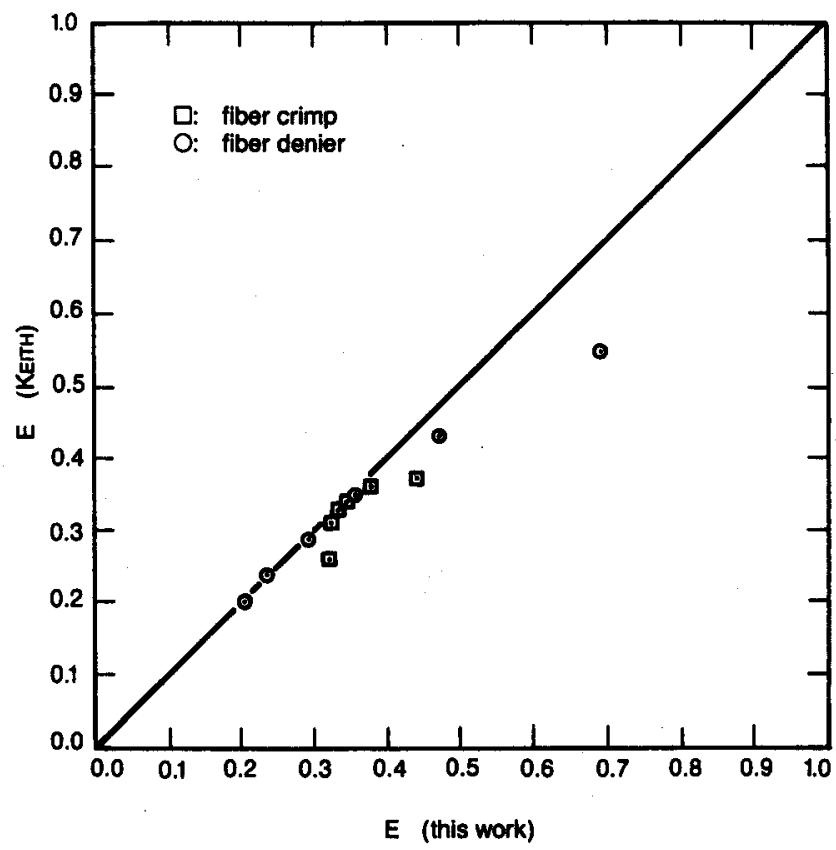

fication, since KerTH's results were calculated not measured, it is encouraging that the two "particle-only" theories show agreement.

KEITH's model also includes the effects of filter fiber denier, filter packing density, tow crimp angle, and filter dimensions. For many of these variables, KerTH provided tables of filter pressure drops and efficiencies, both generated from his formulas. We calculated the efficiencies of these same filters with our model. This was accomplished by using equation 16 with Kerru's values of pressure drop and aerosol flow rate. The correspondence between the two theories is graphically illustrated in Figures 12 and 13. Our model gives very similar results for each of the filter variables with the notable exception of fiber deniers less than 2 , which are outside of the range of our experiments. This agreement demonstrates that the filter pressure drop, at a given flow rate, is by far the dominant predictor of filter efficiency. The influences of filter length, packing density, fiber denier, and crimp angle have a dramatic effect on pressure drop (11), and it is primarily through this factor that these influences are translated into efficiency effects.

The relative roles of diffusion, interception, and impaction on particle removal were ascertained by examining the effects of aerosol flow rate on efficiency. Our results show diffusion to be the major particle capture mechanism at flow rates below $25 \mathrm{~cm}^{3} / \mathrm{s}$. At the standard flow of $17.5 \mathrm{~cm}^{3} / \mathrm{s}$, diffusion accounts for $54 \%$ of a cigarette filter's particulate efficiency. For a $50 \%$ ventilated filter, the upstream filter section will have a diffusional contribution of about $70 \%$. This is the primary reason that ventilated cigarettes have particulate deliv- 
eries which are less than would be expected from dilution considerations alone $(12-14)$.

The total efficiency of a cigarette filter can be partitioned into contributions from condensation and particle capture. The particulate efficiency is primarily a function of the filter pressure drop and aerosol flow rate (equation 16) while the vapor efficiency is dependent on the butt length to which the cigarette is smoked (equation 19).

\section{REFERENCES}

1. Waltz, P., and M. Häusermann: Betrachtungen über die Veränderung des Tabakrauches in der $\mathrm{Ci}$ garette - Die Ausbeute an Rohkondensat, Gesamtwasser, Pyridin, Nikotin, Phenol, Brenzcatechin, Scopoletin und Kohlenoxid im Cigarettenrauch in Abhängigkeit von der Zugnummer und vom Rauchfilter [Reflections on the change in tobacco smoke in the cigarette]; Beitr. Tabakforsch. 3 (1965) 169-202.

2. Mathis, D. E.: Filtration efficiency in ventilated cigarettes; presented at the 36th Tobacco Chemists' Research Conference, Raleigh, North Carolina, 1982.

3. McRae, D. D.: A polydisperse aerosol model for cigarette smoke filtration; presented at the 35th Tobacco Chemists' Research Conference, WinstonSalem, North Carolina, 1981.

4. Ishizu, $Y ., X$. Ohta and T. Okada: Changes in the particle size and the concentration of cigarette smoke through the column of a cigarette; J. Aerosol Sci. 9(1978) 25-29.
5. Fordyce, W. B., I. W. Hughes and M. G. Ivinson: The filtration of cigarette smoke; Tob. Sci. 5 (1961) 70-75.

6. Magee, W. S., L. A. Jonas and W. L. Anderson: Aerosol filtration by fibrous filter mats; in: Removal of trace contaminants from the air, edited by V. R. Dietz, ACS Symposium Series 17, American Chemical Society, Washington, D.C., 1975, pp. 91-105.

7. Hesketh, H. E.: Fine particles in gaseous media; Ann Arbor Science, Ann Arbor, Mich., 1979, p 53.

8. Doorman, R. G.: Filtration; in: Aerosol science, edited by C. N. Davies, Academic Press, New York, N. Y., 1966.

9. Overton, J. R.: Filtration of cigarette smoke Relative contributions of inertial impaction, diffusional deposition, and direct interception; Beitr. Tabakforsch. 7 (1973) 117-120.

10. Keith, C. H.: Physical mechanisms of smoke filtration; Recent Adv. Tob. Sci. 4 (1978) 25-45.

11. Dwyer, R. W.: Predicting the pressure drops across cellulose acetate filters; Beitr. Tabakforsch. Int. 13 (1986) 157-168.

Author's address:

Philip Morris Research Center,

P.O. Box 26583,

Richmond, Virginia, 23261, U.S.A. 